\title{
Landscape planning: functionalism as a motivating concept from landscape ecology and human ecology
}

\author{
Donna L. Hall \\ School of Natural Resources, University of Michigan, Ann Arbor, MI 48109, LSA
}

(Accepted 12 November 1990)

\begin{abstract}
H tll, D.L., 1991. Landscape planning: functionalism as a motivating concept from landscape ecology and human ecology. Landscape Urban Plann., 21: 13-19.

In this paper, the concept of functionalism fr^ $\eta$ both landscape ecology and human ecology is examined. The conceptual merger of these sciences and their application in landscape planning is explored as a basis for an 'ecological approach'. Functionalism is used as a motivating idea, supported by holism and structure as related concepts from ecology. The case is made that alternative ways of thinking about functional relationships have critical relevance to landscape planning. particularly regarding issues of scale and context. Landscape planning for sustainable agriculturai landscapes is used to demonstratc how landscape ccology and human ecology might be merged and applied, and to illustrate how functionalism can be redefined in planning and design.
\end{abstract}

\section{INTRODUCTION}

Landscape ecology, as a multidisciplinary field, is relatively new in North America and is currently receiving considerable attention. The focus of this paper is on the relevance of landscape ecology, combined with human ecology, to applications in landscape planning. Background frameworks, not specific methodologies, are explored in order to help develop a theoretical base that links landscape ecology with planning and design. In the process, this work reviews widely used concepts, not novel or original in the author's work, but fundamental concepts that can be used to thread together landscape planning, as an applied endeavor, and human and landscape ecologies as sciences. The hypothesis of this work is that landscape planning can be an applied marriage of landscape ecology and human ecology. Specifically, an examination of functionalism, as one motivating concept, is used to probe this relationship. At the end of this paper contextual issues in agricultural landscapes are explored to illustrate and support this framework.

\section{ECOLOGY AND PLANNING}

Obviously, landscape ecology and landscape planning share an important connection - the landscape. Paring away the landscape from both pursuits, we find planning and ecology, which share a strong historical and theoretical background, documented by several authors (Young, 1974; Fabos, 1979; Zube, 1986; Berger, 1987; Steiner et al., 1987). In recent decades, an ecological approach has been a prominent theme in planning and design literature. What is an ecological approach? Although the integration of concepts between planning and ecology has been addressed at length in planning and design literature (Rosenburg, 1986), it has been translated to a lesser extent onto the actual landscape. Although ecology and 
planning both deal inextricably with environment as a common denominator, there is not a consensus on what this relationship means in practice. Scholars and practitioners have struggled to provide meaning but we remain quite ignorant about the systems we plan for.

Planning is applied human ecology (Young, 1974). "In reality , course, most planning has been done without realization of these [ecological ] principles. But real urban or regional planners (deserving of the name) must consider the area being planned as a system, must understand its connectedness, its interrelatedness with its own parts and those exterior to it, must understand the flow of people, energy, and materials into and out of it, must understand the design essentials based on environmental characteristics and human nudds. But they do not." (Young, 1974, p. 54.) The argument being made in this paper is that landscape ecology combined with human ecology provides that information.

We do know that there is an urgent need for a better understanding of the relationship between space and society. Late twentieth century landscape planners have devised diverse evaluative and decision-making frameworks based on ecology. The most well-known and influential system is McHarg's classic treatise on designing with nature (McHarg, 1969). Landscape planners seem, more than ever, to be aware of the importance of ecological systems in built environments. Important bridges are being built by landscape theorists such as Lyle (1985), Berger (1987) and Howett (1987) among others, who advocate a broadened perspective in landscape planning and emphasize the need to more fully incorporate ecological knowledge. For instance, building on McHarg's work, Berger (1987) contends that an elaboration is needed, integrating other fields more fully, particularly environmental history, cultural ecology, and cultural geography. He suggests that landscape planning must reach out in both directions from its established core of knowledge - integrating both scientific rigor and humanistic and historic values.

\section{TWO ECOLOGIES}

Perhaps this integration can be organized around two related approaches to ecology, landscape ecology and human ecology. Disciplinary semantics can be a considerable obstacle in conceptually merging various fields of study. For instance, McHarg (1981) has pointed out, while defining human ecological planning, that if humans were accepted as part of ecology and ecology was accepted as part of planning, then ore word - planning - would suffice for three. Semantic difficulties aside, an applied merger is being proposed in this section. Landscape ecology and human ecology share the same ecological roots and a somewhat parallel conceptual evolution over many decades from several disciplines, most notably biology, geography, and sociology.

Landscape ecology is a young discipline in North America and it abstracts itself more from human culture than does its older European counterpart. Landscape ecology concepts were adopted and applied by the landscape design and planning professions in Europe during the late 1960s (Naveh and Lieberman, 1984). Simultaneously in North imerica, McHarg's Design With Nature (1969) was published, and ecological planning and design gained more widespread attention. However, in Europe the linkage of landscape ecology research to applied fields was more strongly developed.

A critical difference can be seen between American and European literature in landscape ecology, in part because of the differing gestation periods of the field on the two continents. European scholars seem more apt to deal with the role of humans in ecological processes. Vink (1983) calls this an anthropocentric approach (not in the literal sense of human-centered, but human-responsible), which puts the responsibility for landscape intervention with people. "It has been argued that the 
antihropocentric approach to landscape ecology dues not only concentrate on the short-term needs of human beings. A proper anthropocentric approach gives full emphasis to the longterm as well as short-term needs, and to the responsibilities of human beings for the landscape and all its organisms." (Vink, 1983, p.5.) This runs parallel to current human ecological approaches in landscape design and planning, which seek more humanistic input (Young et al., 1983; Berger, 1987; Steiner et al., 1987).

Three frameworks - one each from recent landscape ecology, human ecology, and ecosystem design literature - are shown in Table 1 and provide a point of comparison about basic concepts. They are distillations of ideas about how to think about natural systems; all three are derived from basic ecological knowledge. They are being shown here to provide a departure point for discussing functionalism as a motivating concept. These three frameworks have been generated in order to understand patterns, and to make ecological processes more understandable. A summary comparison of these paradigms is provided here before focusing on the concept common to all three function.

Holism is an umbrella concept that covers all three frameworks, although not explicitly framed that way in Forman and Godron's (1986) or Lyle's (1985) scheme. It is, of course, the theory that wholes, as entities, have an existence other than as the mere sum of their parts. People have tried to understand landscapes, and social systems impacting landscapes, in holistic terms for a long time. Hu-

\section{TABLE 1}

Three conceptual frameworks

\begin{tabular}{|c|c|c|}
\hline $\begin{array}{l}\text { Landscape ecology } \\
\text { (Forman and Godron, 1986) }\end{array}$ & $\begin{array}{l}\text { Human ecology } \\
\text { (Young, 1988) }\end{array}$ & $\begin{array}{l}\text { Ecosystem } \\
\text { design } \\
\text { (Lyle, 1985) }\end{array}$ \\
\hline & Holism & \\
\hline Structure & Hierarchy & Structure \\
\hline Change & Interaction & Location \\
\hline Function & Function & Function \\
\hline
\end{tabular}

mans have had a preoccupation with the relationship of parts and wholes; the hierarchies of these connections is an ancient concern. People are intrigued with the way things fit together. However, holism as a method or approach has an indistinct definition (as does an ecological approach ). According to Young, "holism remains murky and controversial, even in ecology, more metaphor than methodology, not so much idea as ideology" $(1988$, p. 37). Holistic study of landscape focuses on pattern and processes in the landscape, including plant, animal and human communities.

Structure is intimately involved with both hierarchy and integration. It refers to the distribution of energy, materials and species. Theories of interaction naturally concern how organisms and systems interact. Out of that, hierarchy theory help explain levels of interaction, or structural relationships among components in landscape or in social processes. Relating Young's framework to Forman and Godron's, interaction and hierarchy especially deal with change and rates of change. The scales and contexts in which we deal with landscapes are changing at increasing rates and with increasing complexity. Numerous reports about the state of the Earth and the interactions among envir nmental variables are revealing a vast panorama of threats to the Earth and human existence. The adjectives 'global' and 'sustainable' are becoming ubiquitous modifiers, not only in science, but in planning and design as well. Where Forman and Godron emphasize temporal aspects - change - in their scheme of landscape characteristics, Lyle emphasizes location as an important component, relating to spatial relationships in a different way than a purely ecological one.

\section{FUNCTIONALISM}

With the concepts above as complementary ideas, functionalism is an important motivating idea for landscape planning based on human ecology and landscape ecology. It is one 
concept of many, on which to succinctly base applications of landscape ecology. Functionalism, in its strictest ecological sense is the study of how components fit together in part-whole relationships (Odum, 1971). It particularly helps explain context in the landscape; context is a common frame of reference for thinking about landscape for planners and designers.

In landscape ecology, function explains how energy, species, water and mineral nutrients flow across the landscape; attention is on the dynamic fluidity of interactions among landscape components. It is inescapably intertwined with structure. Spencer, late in the last century, theorized that "changes of structure cannot occur without changes of function" (1895, p. 459). In Young's human ecology framework, functionalism is used in a parallel way to that of landscape ecology. "Functionalism is the study of connective entities or processes, especially those that connect parts and wholes such as individual and society or individual and environment" (1988, p. 34 ).

The case argued here is that these ways of thinking about functional relationships have critical relevance to landscape planning. "Incomplete though they may be, structure and function are undoubtedly among the most useful of ecological concepts, at least for purposes of design" (Lyle, 1985). However, functionalism in design and planning often has a different connotation, closer to a typical dictionary definition: a doctrine that emphasizes purpose, practicality or usefulness. Related to this basic definition, especially in the design fields, function implies the use of expedient or practical solutions to basic human needs. It has been debased by a certain negative connotation - common or mean. Function has been, of course, a polarized component of the form vs. function dichotomy. Functionalism as a design movement in the early twentieth century advocated design based on fulfilling basic human needs.

A framework for thinking about functionalism in landscape planning must reconcile both the physical theories of functionalism from landscape ecology, with human contextual ideas from human ecology. In the social sciences, the validity of functionalism has been debated at length. Although it has been labeled static and unscientific, it remains a legitimate idea (Young, 1988). I would like to propose that negative or narrow connotations about function are inadequate. It seems that some cultural aspects of landscape, including symbolic, ethical, phenomenological, or perceptual concerns, are truly ecological functions, as much so as nutrient cycling or water flows. In addition, a functional planning solution is not necessarily a less imaginative or sound one. Much of this century's environmental design and planning shows that form cannot necessarily follow function and that form must harmonize as a unity with ecological integrity. The task for landscape ecology, it seems, is to uncover ways that functional connections are established and maintained, determine the strengths with which conrections are bound, and illustrate how connections are manifested in the landscape we experience. The unity of these diverse functional frameworks necessitates different ways of coming to understand landscape, not only in a reductionist way, but in more qualitative and eclectic ways as well.

We continue to plan dysfunctional landscapes (by ecological, aesthetic, or humanistic criteria). If landscape planning is to make the contribution it should, it must synthesize h 1 mans into a functional landscape ecological approach, as much of European landscape ecology has. This stretched definition of functionalism in landscape creates more functional diversity, not only biological diversity but cultural diversity' as well. "Fear of not being able to know, especially with great precision, as well as the comfort of safe knowledge, has retarded synthesis. We remain too atomistic in our approach to scholarship, with every field of knowledge aspiring to the reductionist mode. There is increasing room for a field of study human ecology - that marries the meanest 
with the most meaningful" (Young, 1988, p. 36 ). The same observation could be made about the study of the landscape.

\section{SCALE AND CONTEXT}

“...our life is an apprenticeship to the truth that around every circle another can be drawn. The eye is the first circle; the horizon which it forms is the second; and throughout nature this primary picture is repeated without end." Emerson.

Scale is the central functional question in landscape ecology. Central to landscape ecology theory is the notion that ecosystem concepts are applicable at /arious spatial and temporal scales. As scale changes, so does the fit of landscape parts in the contextual whole. The degree and extent to which changes in scale affect the patterns of organisms are areas of intensive research. The issues addressed in planning are also determined by scale. Scale modifies the approach and influences the level of detail in the planning process. In planning, however, scale is a concept which is limited by political boundaries. Clear references to degrees of interaction between planning scales is often vague. There is "no common language of scale, no system of scales to make these determinations easy and describable. We hear a great deal about 'the large scale' and 'the smaller scale', with no clear notion of what these terms mean" (Lyle, 1985, p. 24). Consequently, 'location' holds a meaningful place in Lyle's conceptual framework for ecosystem design ( Table 1 ).

Scale problems as functional questions have been recognized in the European traditions of landscape-level geography and vegetation science (Meentemeyer and Box, 1987). Explicit coordination of landscape study at various scales is critical to future development in landscape ecology (Forman, 1987). In an applied sense, coordination of work at various scales is fundamental to the future of landscape planning. As soon as landscape planning (and its foundation in landscape and human ecolo- gies) is recognized as a complement to sitespecific landscape design, an holistic approach will be more clearly defined.

Appropriateness of cortext is central to successful design and planning and is intimately tied to issues of scale. Context is the set of circumstances or facts that surround a particular event or situation. It is natural to identify issues of context with those of connotation. Subtie unquantifiable connotations help explain context in the landscape. Some of these subtleties and ambiguities in landscape are interpreted through landscape ecology (and human ecology).

How does critical attention to scale and context affect creativity? It should enhance it. After all, we usually associate creativity with the flexibility of the imagination to shift spheres of reference, in other words, to manipulate context - the ability to symbolize one thing in terms of some other aspect of life. Taking a functionalist perspective is not contradictory to creativity, if it embraces other values (such as aesthetic appeal or psychological satisfaction) as functionally important.

\section{AGRICULTURE AND CONTEXT}

In this final section, agricultural landscape issues illustrate the importance of context and the applicability of landscape and human ecologies. In recent years, agricultural landscapes in developed nations have been under particular scrutiny regarding their ecological integrity. Agriculture is the single largest non-point source of surface-water pollution in the United States and is the primary contributor to groundwater contamination. Pesticide residues in food products have potentially dangerous health effects. At the same time, erosion of precious topsoil has seriously reduced the fertility of US cropland, and modern farming methods require massive amounts of energy to fuel machinery, produce and apply chemicals, and irrigate arid lands (National Research Council, 1989). 
Farmers, agricultural scientists, economists, political leaders and environmental planners are working to transform agriculture. Their motives include preservation of the family farm as a viable economic entity, enhancement of rural communities, prevention of environmental contamination and resource depletion, strer:gthening of ecological resilience and adaptability, and protection of human health and food supplies. Some see agricultural research as a form of social planning that should involve a broader spectrum of disciplines. New approaches place more emphasis on synthesis, moving away from poduction and efficiency as sole functions (Hassebrook, 1989; Macrae et al., 1989).

Agriculture needs a new vision for the physical layout of space. Landscape planning, working with many other disciplines, can make an important contribution toward predicting and building new farming systems. Landscape planners have started to respond in the past decade (Steiner and Theilacker, 1984; Nassauer and Westmacott, 1987). Future work will intricately merge form and function.

With some exceptions, landscape planning is lacking on agricultural lands, beyond the level of the individual farm (and often lacking within farm boundaries in any comprehensive sense). While it would be naive to claim that planning alone would solve the problems listed earlier, clearly the physical processes and patterns of farmed landscapes need to be examined at a hierarchy of scales (Lowrance et al., 1986). Ecological relationships between farms and groups of farms may be as important as on-farm agronomic relationships. Tnis is, of course, where landscape ecology can provide crucial information about functional elements in the agricultural landscape, for instance about hedgerow configurations (Forman and Baudry, 1984), woodlot patches (Muchoki, 1987), or wildlife distribution (Freemark, 1987). Landscape ecology is starting to be used to help structure agricultural land with its understand- able vocabulary of patches, corridors and matrices.

Meshed with landscape ecology, human ecology provides important information about human settlement patterns, social needs, and historical values (Ehrenfield, 1987). Sensitivity to context has largely been abandoned in modern agriculture, leading to a disregard for any 'sense of place'. This is what one researcher calls an 'abstraction crisis' in agriculture, partly explained by a separation of humans from nature (Conviser, 1984). Attention to context can be interpreted as returning qualitative and phenomenological values to agricultural landscapes, perhaps epitomized by the farmer who has the ability to 'read the land'.

The use of functional ideas from landscape ecology and human ecology has enormous potential to address these landscapes in a new way. Researchers interested in more sustainable farming systems are looking at the complexity of interactions between farming and other land uses. Indeed, what some would call functional agricultural landscapes, by economic and production criteria, are dysfunctional using ecological criteria. For example, farm and field sizes are enlarging simultaneously with increases in monocultures of annual crops. In other words, spatial scaies are increasing at the same time that temporal scales are decreasing (Conviser, 1984). This is not only a way to restate the issue in more ecological terms, but a radically different framework in which to see the patterns and processes of agriculture in their larger context. Again, this shift toward understanding functional and contextual relationships can also provide the motivation and foundation for new, creative designs on the land.

\section{ACKNOWLEDGMENT}

The author appreciates the critical input of William W. Budd at the Program in Environmental Science and Regional Planning, Washington State University on earlier versions of 
this paper, as well as the help of Anton J. Jansen and Robert H.G. Jongman at the Agricultural University, Wageningen, The Netherlands.

\section{REFERENCES}

Berger, J., 1987. Guidelines for landscape synthesis: some directions - old and new. Landscape Urban Plann., 14: 295311.

Conviser, R.. 1984. Toward agricultures of context. Environ. Ethics, 6: 71-85.

Ehrenfield, D., 1987. Sustainable agriculture and the challenge of place. Am. J. Alternative Agric., 2: 184-187.

Fabos, J.G., 1979. Planning the Total Landscape: a Guide to Intelligent Land Use. Westview Press, Boulder, CO, 181 pp.

Forman, R.T.T., 1987. The ethics of isolation, the spread of disturbance, and landscape ecology. In: M.G. Turner (Editor), Landscape Heterogeneity and Disturbance. Springer, New York, pp. 214-229.

Forman, R.T.T. and Baudry, J., 1984. Hedgerows and hedgerow networks in landscape ecology. Environ. Manage., 8: 495-510.

Forman, R.T.T. and Godron, M., 1986. Landscape Ecology. Wiley, New York. $619 \mathrm{pp}$.

Freemark, K.. 1987. Agricultural disturbance, wildlife and landscape management. In: M.G. Turner (Editor). Landscape Heterogeneity and Disturbance. Springer. New York, pp. 77-84.

Hassebrook, C... 1989. Testimony to the Agricultural Research and General Legislation Subcommittee of the US Senate Agriculture Commiltee, 9 June, 1989.

Howetl, C., 1987. Systems, signs, sensibilities: sources for a new landscape aesthetic. Landscape J., 6: $1-12$.

Lowrance, R. Hendrix. P.F. and Odum, F.P., 1986. A hierarchical approach to sustainable agriculture. Am. J. Alternative Agric., 1: 169-173.

Lyle, J,T., 1985. Design for Human Ecosystems: Landscape, Land Use and Natural Resources. Van Nosirand Reinhold, Ne: York, 279 pp.

Macrae, R.J., Hill, S.B., Henning, J. and Mehuys, G.R., 1989. Agricultural science and sustainable agriculture: a review of the existing scientific barriers to sustainable food production and potential solutions. Biol. Agric. Hortic.. 3: $173-219$.

McHarg. I., 1969. Design With Nature. Natural History Press. Carden City, New York, 197 pp.

Mcharg. 1.. 1981. Human ecological planning at Pennsylvania. Landscape Plann., 8: 109-120.

Meentemeyer, V. and Box, E.O., 1987. Scale effects in landscape studies. In: M.G. Turner (Editor), Landscape Heterogeneity and Disturbance. Springer, New York. pp. 1534

Muchoki, C.H.K., 1987. Remotely sensed relationships between wooded patch habitats and agricultural landscape type: a basis for ecological planning. In: M.G. Turner (Editor). Landscape Heterogeneity and Disturbance. Springer. New York, pp. 85-94.

Nassauer. J.1. and Westmacott. R.. 1987. Progressiveness among farmers as a factor in heterogeneity of farmed landscapes. In: M.G. Turner (Editor). Landscape Heterogeneity and Disturbance. Springer. New York. pp. 199210

Natronal Research Council. 1989. Alternative Agriculture. National Academy Press, Washington, DC, 448 pp.

Naveh. Z. and Lieberman, A.S., 1984. Landscape Ecology: Theory and Application. Springer, New York, 356 pp.

Odum. E.P., 1971. Fundamentals of Ecology, Saunders, Philadelphia, PA, 555 pp.

Rosenberg, A.M., 1986. An enierging paradigm for landscape architecture. Landscape J., 5: 75-82.

Spencer. H., 1895. The Principles of Sociology, New York.

Stemer. F.R. and Theilacker, J.E., 1984. Protecting Farmlands. Avi, Westport. CT, 312 pp.

Steiner. F.R., Young. G. and Zube. E., i 987. Ecological planm.ng: retrospect and prospect. Landscape J., 7: 31-39.

Vinh. A.P.A., 1983. Landscape Ecology and Land Use. Longman. London, $264 \mathrm{pp}$.

Young, G.E. 1974. Human ecology as an interdisciplinary concep: a critical inquiry. Adv. Ecol. Res., 4: 1-105.

Young, G.E., 1988. A conceptual framework for an interdisciplinary human ecology. Acta Oecol. Hominis, 1: 1-136.

Young, G.F., Steiner, F., Brooks, K. and Struckmeyer, K.. 1983. Determining the regional context for landscape planning. Landscepe Plann., 10: 269-296.

Zube, E.. 1986. The advance of ecology. Landscape Archit., 76: $58-67$. 